\section{Expiratory Rib Cage \\ Compressions to Improve \\ Secretion Clearance During Mechanical Ventilation: Not Only a Matter of Squeezing the Chest- Reply}

In Reply:

We thank Dr Martí and his colleagues for their comments on our study. The different methods used to investigate the clinical and physiological repercussions of airway clearance techniques make comparison between studies difficult. Animal studies like those from Unoki et $\mathrm{al}^{1,2}$ and Martí et $\mathrm{al}^{3}$ are important to elucidate mechanisms and raise insights into safety and efficacy of clinical studies with human participants. However, compared with animal models, most mechanically ventilated patients are not paralyzed and present with diverse clinical conditions and respiratory mechanics profiles.

The rational of chest physiotherapy is to displace secretions from the periphery to more central airways, where they can be removed by coughing. ${ }^{4}$ In our study, similar to the forced expiratory technique, we used prolonged strong manual compression aimed at improving the 2-phase gas-liquid flow in lung periphery. ${ }^{4,5}$ Our results showed that, according to expiratory flow-volume loop monitoring, this maneuver increased not only the peak expiratory flow but also the air flow throughout the entire expiratory phase in most subjects. ${ }^{6}$ Conversely, because the brief strong expiratory maneuver in the study by Martí et $a^{3}$ increased the peak expiratory flow, it was considered an exogenous cough. ${ }^{7}$ Moreover, the increase in mucus displacement velocity in the central airways (trachea) observed in their study is an expected result and does not reflect mobilization of secretions from the lung periphery.
In conceptual terms, a distinction has to be made between any abrupt expiratory manual compressive maneuver, which mimics the attributes of an effective spontaneous cough, and prolonged expiratory rib cage compression as a technique to remove secretions from the lung periphery. The first, also called directed cough or manually assisted cough, consists of "assisting the cough effort with abdominal or thoracic compression during exhalation"4 and has been indicated to improve the peak expiratory flow in patients with weak cough. ${ }^{8,9}$ Because the hard manual rib cage compressions in the study by Martí et al $^{3}$ were applied only in the early expiratory phase, we question whether it can be compared with a directed cough maneuver or an exogenous cough

To date, the literature has not shown any benefit in mobilizing peripheral secretions by rapidly squeezing out air with prolonged strong compressions (manually assisted cough), brief strong manual compressions synchronized with the early expiratory phase (hard manual rib cage compressions), or prolonged strong and slow manual compressions throughout the entire expiration phase (expiratory rib cage compression) in mechanically ventilated patients.

Fernando S Guimarães PT PhD Sara Lucia Silveira de Menezes PT PhD

Rehabilitation Sciences Master's Program Augusto Motta University Center and

School of Physiotherapy

Federal University of Rio de Janeiro Rio de Janeiro, Brazil

Agnaldo J Lopes MD PhD Rehabilitation Sciences Master's Program Augusto Motta University Center and Pedro Ernesto Hospital Rio de Janeiro State University Rio de Janeiro, Brazil
The authors have disclosed no conflicts of interest.

\section{REFERENCES}

1. Unoki T, Mizutani T, Toyooka H. Effects of expiratory rib cage compression and/or prone position on oxygenation and ventilation in mechanically ventilated rabbits with induced atelectasis. Respir Care 2003; 48(8):754-762.

2. Unoki T, Mizutani T, Toyooka H. Effects of expiratory rib cage compression combined with endotracheal suctioning on gas exchange in mechanically ventilated rabbits with induced atelectasis. Respir Care 2004;49(8):896-901.

3. Martí JD, Li Bassi G, Rigol M, Saucedo L, Ranzani OT, Esperatti M, et al. Effects of manual rib cage compressions on expiratory flow and mucus clearance during mechanical ventilation. Crit Care Med 2013; 41(3):850-856.

4. Fink JB. Forced expiratory technique, directed cough, and autogenic drainage. Respir Care 2007;52(9):1210-1221; discussion 1221-1223.

5. Van der Schans CP. Bronchial mucus transport. Respir Care 2007;52(9):1150-1156; discussion 1156-1158.

6. Guimarães FS, Lopes AJ, Constantino SS, Lima JC, Canuto P, de Menezes SL. Expiratory rib cage compression in mechanically ventilated subjects: a randomized crossover trial. Respir Care 2014;59(5): 678-685.

7. Siner JM. An exogenous cough. Crit Care Med 2013;41(3):929-930.

8. Bach JR, Gonçalves MR, Hon A, Ishikawa Y, De Vito EL, Prado F, Dominguez ME. Changing trends in the management of endstage neuromuscular respiratory muscle failure: recommendations of an international consensus. Am J Phys Med Rehabil 2013;92(3):267-277.

9. Ambrosino N, Carpenè N, Gherardi M. Chronic respiratory care for neuromuscular diseases in adults. Eur Respir J 2009;34(2): $444-451$. 